\title{
EDITORIAL
}

\section{A New Scope and a New Editorial Team for The American Journal of Pathology}

\author{
Martha B. Furie*
}

From the Department of Pathology, Stony Brook University, Stony Brook, New York (Editor-in-Chief)

The first issue of The American Journal of Pathology (AJP) was published on January 1, 1925. I am grateful that $A J P$ has been an important part of my professional life for 25 years of its 93-year existence. Five of its 12 Editors-in-Chief have given me the opportunity to serve the Journal, first with Dr. Nelson Fausto's invitation to join the Editorial Board in 1993 and most recently with my appointment by Dr. Kevin Roth as Senior Associate Editor from 2013 to 2017. Now I am honored and humbled to have been selected by my colleagues in the American Society for Investigative Pathology (ASIP) to be the next Editor-in-Chief of its flagship publication. I am the first woman in this position, and it is a testament to the support that I have received throughout my career that this is the only glass ceiling that I have broken. My selection also underscores ASIP's commitment to provide opportunities for all of its members; notably, three of the last nine presidents of the Society were women, as are the current President-Elect and Vice President.

My long relationship with $A J P$ has familiarized me with trends in its content, and I gained even more insight when Dr. Richard (Rick) Mitchell and I wrote an article ${ }^{1}$ as part of ASIP's centennial commemoration in 2013. In this review, we discussed the history of research on atherosclerosis as reflected by articles published in $A J P$, starting with that very first issue in 1925. Preparing the review deepened my appreciation of the preeminent role that the Journal, since its inception, has played in promoting the discipline of pathology. I also was struck by the changing scope of the research that has appeared in its pages, with every Editorin-Chief executing his own vision for the types of investigations to be published. For many years, the scope of the Journal encompassed both observational and experimental pathology. In 1982, however, then Editor-in-Chief Vincent Marchesi explicitly placed a higher priority on mechanistic studies. This priority was emphasized when the tag line Cellular and Molecular Biology of Disease was added to the masthead of AJP in 1994.
Today, the boundary between descriptive and mechanistic investigations in pathology has become blurred. New technologies allow for the generation of large data sets that inform future correlative and mechanistic inquiries. In 2008, Editor-in-Chief Michael Lisanti accordingly broadened the scope of $A J P$ to include translational research. But the manuscripts that are currently received for review suggest that many potential authors are under the impression that the Journal accepts only research with a strong mechanistic component. To clarify the kinds of content that AJP considers, ASIP's governing Council has approved a new statement of scope, which appears for the first time in this issue:

The American Journal of Pathology, official journal of the American Society for Investigative Pathology and published by Elsevier, Inc., seeks high-quality original research reports, reviews, and commentaries related to the molecular and cellular basis of disease. The editors will consider basic, translational, and clinical investigations that directly address mechanisms of pathogenesis or provide a foundation for future mechanistic inquiries. Examples of such foundational investigations include data mining, identification of biomarkers, molecular pathology, and discovery research. High priority is given to studies of human disease and relevant experimental models using molecular, cellular, and organismal approaches.

To further highlight this expanded scope, the previous tag line on AJP's masthead has been replaced with Discoveries in Basic and Translational Pathobiology. The Editors hope that these revisions emphasize to readers and authors that we recognize the changing nature of research in pathology and want the pages of $A J P$ to reflect this evolution.

I am very fortunate to be taking on the Editor-in-Chief position at a time when $A J P$ has benefited from outstanding leadership and management. Under Dr. Roth's direction and with the support of the Editorial Office staff, the past five years

Accepted for publication October 26, 2017. 
have seen streamlining of editorial procedures; reduction of publication fees; a markedly shorter turnaround time for processing and posting of manuscripts; increased content of timely review articles; implementation of Theme Issues; and establishment of a strong presence on social media. AJP now has over 1600 followers on Twitter (@AJPathology) and more than 2500 on Facebook (https://www.facebook.com/ AJPathology). Nonetheless, multiple factors are currently creating a very challenging environment for scientific publishing. As is the case for many comparable journals, $A J P$ has experienced steady decreases over the past decade in its two-year impact factor and number of submissions. Encouragingly, AJP remains first among 79 pathology journals in terms of total number of citations and Eigenfactor, a metric designed to measure the overall impact of a journal on its field (https://jcr.incites.thomsonreuters. com, last accessed October 19, 2017; registration required).

What, then, can be done to build on AJP's strengths and better equip it to face the challenges that lie ahead? The obvious measures have already been put into effect under Dr. Roth's leadership, but complacency is not an option. We need a multifaceted, team-based approach that focuses on development of content, new marketing strategies, and greater outreach to the pathology community. To that end, I am very grateful that William (Bill) Coleman, Ph.D., and Rick Mitchell, M.D., Ph.D., have joined AJP as Senior Associate Editors. Dr. Coleman investigates cancer epigenetics and molecular signatures, with emphasis on breast cancer. He is a Professor in the Department of Pathology and Laboratory Medicine at the University of North Carolina School of Medicine, a member of the UNC Lineberger Comprehensive Cancer Center, and Director of the UNC Program in
Translational Medicine. Dr. Mitchell's research explores the mechanisms underlying acute and chronic solid organ allograft rejection. He is the Vice Chair for Education at Brigham and Women's Hospital and Associate Director of the Harvard-MIT Health Sciences and Technology program at Harvard Medical School, where he is a full Professor. Additionally, Drs. Coleman and Mitchell both have a long history of dedicated service to ASIP in senior elected positions.

To round out our team, we are extremely fortunate to have inherited the support of AJP's publisher, Elsevier, Inc.; ASIP's Marketing and Communications Manager, Gina LaBorde; and AJP's devoted and highly experienced editorial staff: Emily Essex, Managing Editor; Henry Carter, Assistant Managing Editor; Chhavi Chauhan, Ph.D., Scientific Editor; and Michael Dustin, Senior Editorial Assistant. Collectively, we have revised the Journal's scope and generated an extensive list of innovations that will be rolled out in the coming weeks and months.

Lastly, we invite you - AJP's readers, authors, Associate Editors, and Editorial Board members - to become part of our team. We welcome your suggestions for improving the Journal, which can be sent to the Editorial Office at ajp@ asip.org. Together, we will strive to enhance the stature of The American Journal of Pathology and ensure that it remains a premier forum for dissemination of the latest findings in investigative pathology for many years to come.

\section{Reference}

1. Furie MB, Mitchell RN: Plaque attack: one hundred years of atherosclerosis in The American Journal of Pathology. Am J Pathol 2012, 180: 2184-2187 